\title{
РАЗРАБОТКА И ВАЛИДАЦИЯ МЕТОДИКИ ОПРЕДЕЛЕНИЯ 2-ДИМЕТИЛАМИНО-1,3-БИС- (ФЕНИЛСУЛЬФОНИЛТИО)ПРОПАНА В ТКАНИ ГНИЛОСТНО ИЗМЕНЁННОЙ ПЕЧЕНИ
}

\author{
(C) Баранов Ю.Н., Шорманов В.К., Нестерова А.В., Коваленко Е.А.
}

\author{
Кафедра фармацевтической, токсикологической и аналитической химии \\ Курского государственного медицинского университета, Курск \\ E-mail: R-WLADIMIR@yandex.ru
}

\begin{abstract}
Исследованы особенности изолирования 2-диметиламино-1,3-бис-(фенилсульфонилтио)пропана (бенсултапа) из искусственных смесей с тканью гнилостно измененной печени этилацетатом в режиме инфузии. Для извлечения 75,39-75,42 \% 2-диметиламино-1,3-бис-(фенилсульфонилтио)-пропана этилацетатом из гнилостно измененной печени необходимо двукратное настаивание биологической матрицы с этилацетатом при соотношении масс изолирующей жидкости и биологического объекта 2:1 и продолжительности каждого этапа инфузии 30 минут. Очистка выделенного вещества от эндогенных веществ биоматрицы осуществляется методом макроколоночной хроматографии (неподвижная фаза - силикагель L 40/100 мкм, элюенты - гексан и смесь гексан-диоксан-пропанол-2 (8:3:0,6)). Разработана методика определения 2-диметиламино-1,3-бис-(фенилсульфонилтио)пропана (бенсултапа) в ткани гнилостно измененной печени с использованием варианта нормальнофазовой ВЭЖХ. Методика валидирована по показателям линейности, правильности, прецизионности, стабильности. Пределы обнаружения и количественного определения 2-диметиламино-1,3-бис-(фенилсульфонилтио)пропана составляют соответственно $3,15 \cdot 10^{-6}$ г и 4,0 10 ${ }^{-6}$ г в 1 г биоматериала.
\end{abstract}

Ключевые слова: 2-диметиламино-1,3-бис-(фенилсульфонилтио)-пропан (бенсултап), изолирование, очистка, идентификация и определение, валидация.

\section{DEVELOPMENT AND VALIDATION OF PROCEDURE FOR DETERMINING 2-DIMETHYLAMINO-1.3-BIS- (PHENYLSULFONYLTHIO) PROPANE IN PUTREFIED LIVER TISSUE Baranov Yu.N., Shormanov V.K., Nesterova A.V., Kovalenko E.A.}

Department of Pharmaceutical, Toxicological and Analytical Chemistry of Kursk State Medical University, Kursk

Special features of isolating ethyl acetate of 2-dimethylamino-1.3-bis-(phenylsulfonylthio) propane (bensultap) from its artificial mixtures with the putrefied liver tissue upon infusion mode have been investigated. Double infusion of biological matrix with ethyl acetate at a mass ratio of isolation liquid to biologic object 2:1 and the 30 minutes running time of each infusion stage were necessary to isolate 75.39-75.42 \% of 2-dimethylamino-1.3-bis-(phenylsulfonylthio) propane (bensultap) from putrescent liver. Purification of the isolated substance from endogenous compounds has been carried out by the method of micro-column chromatography (stationary phase - silica gel L 40/100 $\mu \mathrm{m}$, eluents - hexane and a mixture of hexane-dioxanepropanol-2 (8: 3: 0.6)). The procedure for determining 2-dimethylamino-1.3-bis-(phenylsulfonylthio) propane (bensultap) in the putrefied liver tissue $f$ by using normal-phase HLPC variant has been worked out. The procedure proposed has been validated by criteria of linearity, trueness, precision, and stability. Detection limit and quantitation limit for 2-dimethylamino-1.3bis-(phenylsulfonylthio) propane were correspondently $3.1510^{-6} \mathrm{~g}$ and $4.010^{-6} \mathrm{~g}$ per $1 \mathrm{~g}$ of biomaterial.

Keywords: 2-dimethylamino-1.3-bis-(phenylsulfonylthio) propane (bensultap), isolation, purification, identification and assay, validation.

2-Диметиламино-1,3-бис-(фенилсульфонилтио)пропан (1,3-бис(бензолсульфонилсульфанил)$\mathrm{N}, \mathrm{N}$-диметилпропан-2-амин); устоявшееся название бенсултап; торговые наименования: банкол, Ambcb5157213, дибензолсульфонат нереистоксина, BRN 2228033, виктенон, рубан (далее по тексту - 2-ДМА-1,3-бис-(ФСТ)П) - биологически активное соединение антихолинэстеразного действия, обладающее свойствами инсектицида $[3,4$, 9].

2-ДМА-1,3-бис-(ФСТ)П - это белое с незначительным коричневатым оттенком кристаллическое вещество (температура плавления $84-85^{\circ} \mathrm{C}$ ). 2-ДМА-1,3-бис-(ФСТ)П плохо растворим в воде (при $30^{\circ} \mathrm{C}$ 0,7-0,8 г/л), а также в кисло-водных растворах. Хорошую растворимость (при $25^{\circ} \mathrm{C}$
$>1000$ г/кг) вещество обнаруживает в трихлорметане, ацетонитриле и диметилкетоне. При $25^{\circ} \mathrm{C}$ растворимость (г/кг) 2-ДМА-1,3-бис-(ФСТ)П в метаноле составляет 25 , в этаноле - 13 , в гексане - $0,17[8,10,16]$.

2-ДМА-1,3-бис-(ФСТ)П оказывает токсическое действие на теплокровные организмы. $\mathrm{LD}_{50}$ при введении данного соединения внутрижелудочно крысам немного превышает 1 г/кг. Регулярно отмечаются случаи отравления людей 2-ДМА-1,3-бис-(ФСТ)П и рядом близких к нему по структуре и свойствам веществ $[11,12]$.

Определенный процент отравлений рассматриваемым веществом заканчивался летальным исходом. Отравления 2-ДМА-1,3-бис-(ФСТ)П со смертельным исходом отмечены в странах Цен- 
тральной Азии, Индокитая, ряде европейских государств [13-15].

Несколько летальных исходов от отравления данным соединением зарегистрировано в Центрально-Черноземном регионе Российской Федерации, а также на территории Республики Украина. В районе г. Киева за период с 1993 по 2013 год пятая часть всех отравлений приходилась на отравления 2-ДМА-1,3-бис-(ФСТ)П [1, 2, $5]$.

Наличие многочисленных отравлений 2-ДМА-1,3-бис-(ФСТ)П на территории Российской Федерации, многих стран Азии и Европы позволяет считать данное вещество важным объектом судебно-химического анализа и делает необходимым изучение особенностей его изолирования из биологических объектов, очистки и определения.

Продолжают оставаться малоизученными некоторые направления судебно-химического анализа 2-ДМА-1,3-бис-(ФСТ)П, состоящие в разработке методик его определения в тканях органов, подвергшихся гнилостным изменениям, и валидации этих методик.

Цель настоящего исследования - разработка методики определения 2-диметиламино-1,3-бис(фенилсульфонилтио)пропана в ткани гнилостно измененной печени и валидация разработанной методики.

\section{МАТЕРИАЛЫ И МЕТОДЫ ИССЛЕДОВАНИЯ}

Объект исследования - 2-диметиламино-1,3бис-(фенилсульфонилтио)пропан) (2-ДМА-1,3бис-(ФСТ)П), ч., СОП 342-034-2003, не менее 97\% основного компонента. Структуру данного соединения отражает формула:

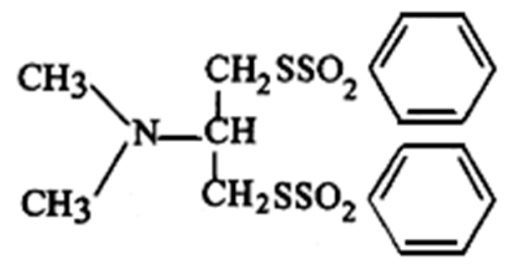

Принимая во внимание данные ранее проведенных экспериментальных исследований, в качестве оптимального изолирующего агента был выбран этилацетат, позволяющий достигать высоких значений степени извлечения соединений с невыраженными кислотно-основными свойствами, к которым относится и 2-ДМА-1,3-бис(ФСТ)П, а также обеспечивающий получение достаточно чистых извлечений из биологических тканей [6].

Для проведения экспериментов готовили искусственные смеси 2-ДМА-1,3-бис-(ФСТ)П с тка- нью гнилостно измененной печени (содержание исследуемого вещества $0,1 \%$ ) и оставляли их на 90 мин при $18-22^{\circ} \mathrm{C}$.

2-ДМА-1,3-бис-(ФСТ)П дважды по 45 минут извлекали из приготовленных биологических объектов этилацетатом в режиме инфузии при массовом соотношении «изолирующий агент ткань печени» 2:1. Первое и второе извлечения объединяли, часть общего извлечения наносили в виде полосы на линию старта пластины «Сорбфил» ПТСХ-АФ-А-УФ и хроматографировали, используя подвижную фазу гексан-диоксанпропанол-2-ацетон $(8: 3: 0,8: 0,8)$.

При проявлении хроматограмм в УФ-свете ( $\lambda=254$ нм) на них обнаруживались темные пятна c $\mathrm{Rf}=0,56 \pm 0,03$, соответствующие 2-ДМА-1,3бис-(ФСТ)П. Фрагмент пластины с пятном исследуемого вещества вырезали из пластины и элюировали вещество 95\% этанолом в течение 15 минут. Интенсивность поглощения элюата измеряли при длине волны 255 нм на приборе СФ-46 в кювете с толщиной рабочего слоя 10 мм. Количество извлечённого из ткани гнилостно измененной печени 2-ДМА-1,3-бис-(ФСТ)П рассчитывали, используя уравнение градуировочного графика. По приведенной схеме исследовали влияние на полноту извлечения анализируемого соединения из искусственных смесей с тканью гнилостно измененной печени ряда факторов (продолжительности каждого этапа настаивания, соотношения масс изолирующей жидкости и биологического объекта, кратности настаивания).

$\mathrm{B}$ найденных оптимальных условиях изучалась зависимость степени извлечения 2-ДМА-1,3бис-(ФСТ)П от его содержания в биологической ткани. Для исследования брали искусственные смеси с содержанием аналита $0,005-0,2 \%$.

Проводили исследования по определению оптимальных условий очистки 2-ДМА-1,3-бис(ФСТ)П от возможных эндогенных веществ биоматрицы в макроколонке $160 \times 10$ мм силикагеля L с размерами частиц 40-100 мкм при использовании мало- и среднеполярных подвижных фаз. Присутствие 2-ДМА-1,3-бис-(ФСТ)П во фракциях обнаруживали методом ТСХ в соответствии с приводимыми выше условиями.

Для идентификации и количественного определения 2-ДМА-1,3-бис-(ФСТ)П применяли вариант нормальнофазовой ВЭЖХ, используя колонку размерами 64 мм $\times 2$ мм с сорбентом «Силасорб600» и прибор «Милихром», снабженный УФ-детектором).

На основе предварительных исследований разрабатывалась методика определения 2-ДМА1,3-бис-(ФСТ)П в ткани гнилостно измененной печени и проводилась валидация по установленным правилам [7]. 
Установлено, что достаточно полно 2-ДМА1,3-бис-(ФСТ)П изолируется из ткани гнилостно измененной печени этилацетатом уже в условиях двукратного настаивание биоматериала с изолирующим агентом, если на каждом этапе изолирования масса изолирующей жидкости превышает массу биологического объекта как минимум в два раза, а продолжительность каждого этапа составляет не менее 30 мин.

Оптимальные условия хроматографирования ликагеля типа «L» состоят в том, что через колонку вначале пропускают неполярный гексан, после выхода 20 мл гексана его слой над поверхностью сорбента удаляют, а в колонку начинают подавать систему растворителей гексан - диоксан - пропанол-2 (8:3:0,6). С момента начала подачи системы начинается сбор фракций элюата по 2 мл каждая. 2-ДМА-1,3-бис-(ФСТ)П элюируется фракциями с 11 по 14 (21-28 мл).

Для определения 2-ДМА-1,3-бис-(ФСТ)П методом ВЭЖХ в качестве подвижной фазы предложена смесь растворителей гексан-диоксанпропанол-2 (15:5:1). Скорость элюирования 100 мкл/мин, скорость ленты самописца 720 мм/час, масштаб регистрации - 0,8 ед.о.п., аналитическая длина волны - 256 нм.

При воспроизведении предложенных условий время удерживания рассматриваемого вещества составляет 6,36 мин, относительное удерживание - 1,53 , коэффициент емкости $-3,04$, число теоретических тарелок - 2257.

Результаты определения степени извлечения 2-ДМА-1,3-бис-(ФСТ)П из искусственных смесей при содержании аналита в биоматериале $0,01-0,2 \%$ представлены в табл. 1 .

Как свидетельствуют полученные данные, предлагаемые условия позволяют выделить из ткани гнилостно измененной печени $75,39-75$, $42 \%$ 2-ДМА-1,3-бис-(ФСТ)П от первоначально внесенных количеств.

\section{РЕЗУЛЬТАТЫ ИССЛЕДОВАНИЯ И ИХ ОБСУЖДЕНИЕ} анализируемого соединения в макроколонке си-

На основе предварительных исследований разработана методика определения 2-ДМА-1,3бис-(ФСТ)П в ткани гнилостно измененной печени с использованием метода нормальнофазовой ВЭЖХ.

Методика определения 2-ДМА-1,3-бис(ФСТ)П в ткани гнилостно измененной печени. 10 г ткани гнилостно измененной печени, содержащей анализируемое соединение, 30 минут настаивали с 20 г этилацетата при периодическом перемешивании. Извлечение отделяли от твердых частиц биоматериала, а процесс настаивания повторяли в описанных условиях. Оба извлечения объединяли, фильтровали через безводный сульфат натрия (толщина слоя 1-1,5 см), слой сульфата натрия промывали 10 г этилацетата. Фильтрат и промывную жидкость объединяли в выпарительной чашке, растворитель испаряли в токе воздуха при температуре $18-22^{\circ} \mathrm{C}$.

Полученный остаток растворяли в 4 мл трихлорметана, 2 мл раствора смешивали с 1 г силикагеля L 40/100 мкм и удаляли трихлорметан из сорбента в токе воздуха.

В стеклянную колонку размером $490 \times 10$ мм помещали вначале 9 г силикагеля L 40/100 мкм, a потом, поверх сформированного слоя, помещали 1 г силикагеля L 40/100 мкм, содержащего 2-ДМА-1,3-бис-(ФСТ)П, добавленный в виде трихлорметанового раствора. Процесс элюирования и сбора фракций элюата осуществляли по приведенной выше схеме. Фракции с 11 по 14 включительно сливали вместе в выпарительную чашку и удаляли элюент в токе воздуха при температуре $18-22^{\circ} \mathrm{C}$. Остаток растворяли в 5 мл диоксана. 2,0 мл полученного диоксанового раствора вносили в выпарительную чашку и упаривали в токе воздуха при комнатной температуре до сухого остатка. Остаток растворяли в смеси 1,0 мл диоксана и 0,2 мл пропанола-2, к раствору прибавляли 3 мл гексана, переносили в мерную колбу вместимостью 5 мл и доводили содержимое колбы до метки системой растворителей гександиоксан-пропанол-2 (15:5:1). 16 мкл содержимого колбы вводили в хроматограф.

Таблица 1

Результаты определения степени извлечения 2-диметиламино-1,3-бис-(фенилсульфонилтио)пропана этилацетатом из ткани гнилостно измененной печени после очистки методом макроколоночной хроматографии $(\mathrm{n}=5, \mathrm{P}=0,95)$

\begin{tabular}{|c|c|c|c|c|}
\hline \multirow{2}{*}{$\begin{array}{c}\text { Содержание 2-диметиламино-1,3-бис-(фенилсульфонилтио)- } \\
\text { пропана в ткани гнилостно измененной печени, \% }\end{array}$} & \multicolumn{4}{|c|}{ Степень извлечения, \% } \\
\hline & $\bar{x}$ & $\mathrm{~S}$ & $\mathrm{~S}_{\bar{x}}$ & $\Delta \bar{x}$ \\
\hline 0,2 & 74,01 & 2,49 & 1,11 & 3,10 \\
\hline 0,1 & 73,66 & 2,71 & 1,21 & 3,37 \\
\hline 0,04 & 73,44 & 2,85 & 1,27 & 3,53 \\
\hline 0,02 & 72,91 & 3,31 & 1,48 & 4,12 \\
\hline 0,01 & 72,20 & 3,77 & 1,68 & 4,70 \\
\hline
\end{tabular}






Рис. 1. Хроматограмма (ВЭЖХ) 2-диметиламино-1,3-бис-(фенилсульфонил-тио)пропана (1), извлеченного из ткани гнилостно измененной печени, в присутствии тетраметилтиурамдисульфида (внутренний стандарт) (2).

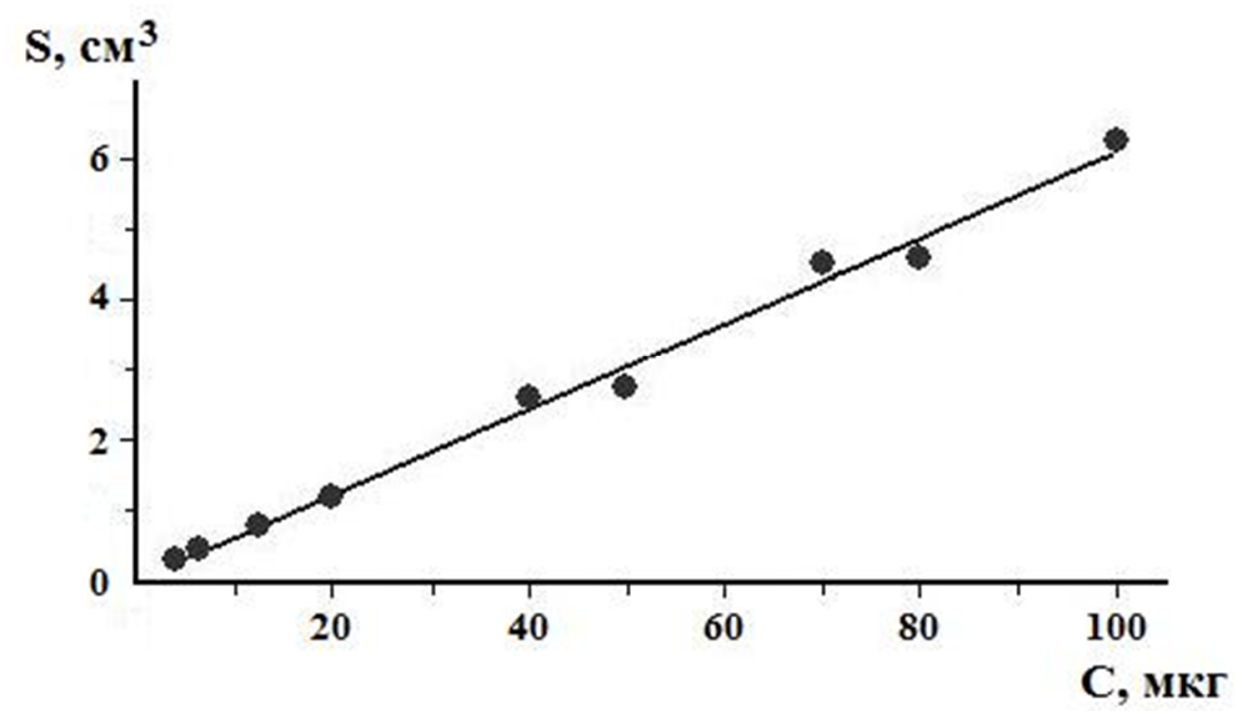

Рис. 2. Градуировочный график зависимости площади хроматографического пика $\left(\mathrm{S}, \mathrm{cm}^{3}\right)$ от концентрации 2-диметиламино-1,3-бис-(фенилсульфонилтио)пропана в ткани гнилостно измененной печени $(\mathrm{C}, \mathrm{мкг} / \Gamma)$.

2-ДМА-1,3-бис-(ФСТ)П идентифицировали по времени удерживания $(6,36 \pm 0,05)$. Хроматограмма исследуемого соединения, извлеченного из ткани гнилостно измененной печени, в присутствии внутреннего стандарта изображена на рис. 1.

Оценку количественного содержания объекта исследования в биоматрице проводили, принимая во внимание площадь хроматографического пика и используя уравнение градуировочного графика.

Валидационные мероприятия. Проводили валидационные мероприятия для разработанной методики по параметрам линейности, правильно- сти, прецизионности, селективности, пределов обнаружения и определения.

Линейность. В рамках каждого аналитического цикла готовили искусственные смеси биоматериала (ткани гнилостно измененной печени) и 2-ДМА-1,3-бис-(ФСТ)П с содержанием исследуемого вещества $4,0,6,25,12,5,20,40,50,70,80$ и 100 мкг/г, после чего их выдерживали 90 минут при $18-22^{\circ} \mathrm{C}$. Через указанный промежуток времени изолировали 2-ДМА-1,3-бис-(ФСТ)П из искусственных смесей, подвергали очистке, а затем идентифицировали и количественно определяли по указанной выше схеме. 
Таблица 2

Отклонения найденных концентраций градуировочных смесей с тканью гнилостно измененной печени от истинного содержания в них 2-диметиламино-1,3-бис-(фенилсульфонилтио)пропана

\begin{tabular}{|c|c|c|}
\hline $\begin{array}{c}\text { Истинное содержание 2-диметиламино-1,3-бис- } \\
\text { (фенилсульфонилтио)-пропана, мкг/г }\end{array}$ & $\begin{array}{c}\text { Найденное содержание } \\
\text { 2-диметиламино-1,3-бис- } \\
\text { (фенилсульфонилтио)-пропана мкг/г }\end{array}$ & $\begin{array}{c}\text { Относительная } \\
\text { погрешность, \% }\end{array}$ \\
\hline 4 & 4,7161 & 17,90 \\
\hline 6,25 & 7,0499 & 12,80 \\
\hline 12,5 & 12,4920 & $-0,001$ \\
\hline 20 & 19,3920 & $-3,04$ \\
\hline 40 & 42,4130 & 6,03 \\
\hline 50 & 44,5327 & $-10,94$ \\
\hline 70 & 74,0870 & 5,84 \\
\hline 80 & 75,1906 & $-6,01$ \\
\hline 100 & 102,7992 & 2,80 \\
\hline
\end{tabular}

Допустимые пределы: для наименьшей концентрации линейного диапазона - не более $20 \%$, для остальных концентраций линейного диапазона - не более $15 \%$

Таблица 3

Оценка правильности и прецизионности методики определения 2-диметиламино-1,3-бис(фенилсульфонилтио)пропана в ткани гнилостно измененной печени с использованием нормальнофазовой ВЭЖХ

\begin{tabular}{|c|c|c|c|}
\hline $\begin{array}{c}\text { Внесено аналита, мкг в } 1 \text { г } \\
\text { биоматрицы }\end{array}$ & $\begin{array}{c}\text { Найдено, мкг в } 1 \text { г } \\
\text { биоматрицы }\end{array}$ & $\begin{array}{r}\text { Относительная } \\
\text { погрешность, \% }\end{array}$ & Метрологические характеристики \\
\hline \multicolumn{4}{|c|}{ Исследование в первый день } \\
\hline 12,5 & 12,64 & \multirow[t]{5}{*}{7,28} & \multirow{5}{*}{$\begin{array}{c}x=13,41 ; \mathrm{S}=1,0729 ; \\
\mathrm{S}_{\bar{x}}=0,4798 ; \\
\Delta \bar{x}=1,3338 ; \bar{\varepsilon}=9,95 ; \mathrm{S}_{\mathrm{r}}=8,00 \%\end{array}$} \\
\hline 12,5 & 13,88 & & \\
\hline 12,5 & 14,95 & & \\
\hline 12,5 & 12,22 & & \\
\hline 12,5 & 13,36 & & \\
\hline 40 & 38,66 & \multirow[t]{5}{*}{$-6,18$} & \multirow{5}{*}{$\begin{array}{l}x=37,528 ; \mathrm{S}=2,1435 ; \\
\mathrm{S}_{\bar{x}}=0,9586 ; \\
2,6649 ; \bar{\varepsilon}=7,10 ; \mathrm{S}_{\mathrm{r}}=5,7117 \%\end{array}$} \\
\hline 40 & 34,58 & & \\
\hline 40 & 40,33 & & \\
\hline 40 & 36,85 & & \\
\hline 40 & 37,22 & & \\
\hline 80 & 75,63 & \multirow[t]{5}{*}{$-8,58$} & \multirow{5}{*}{$\begin{array}{c}x=73,134 ; \mathrm{S}=3,5594 ; \\
\mathrm{S}_{\bar{x}}=1,5918 ; \\
4,4252 ; \overline{\mathcal{E}}=6,05 ; \mathrm{S}_{\mathrm{r}}=4,8670 \%\end{array}$} \\
\hline 80 & 77,89 & & \\
\hline 80 & 72,34 & & \\
\hline 80 & 69,49 & & \\
\hline 80 & 70,32 & & \\
\hline \multicolumn{4}{|c|}{ Исследование в последующий день } \\
\hline 12,5 & 14,8 & \multirow[t]{5}{*}{12,51} & \multirow{5}{*}{$\begin{array}{c}\bar{x}=14,064 ; \mathrm{S}=1,1949 ; \\
\quad \mathrm{S}_{\bar{x}}=0,5344 ; \\
1,4855 ; \bar{\varepsilon}=10,56 ; \mathrm{S}_{\mathrm{r}}=8,495 \%\end{array}$} \\
\hline 12,5 & 13,04 & & \\
\hline 12,5 & 12,64 & & \\
\hline 12,5 & 15,48 & & \\
\hline 12,5 & 14,36 & & \\
\hline 40 & 43,39 & \multirow[t]{5}{*}{4,23} & \multirow{5}{*}{$\begin{array}{c}\bar{x}=41,692 ; \mathrm{S}=2,4458 ; \\
\mathrm{S}_{\bar{x}}=1,0938 ; \\
\Delta \bar{x}=3,0408 ; \bar{\varepsilon}=7,29 ; \mathrm{S}_{\mathrm{r}}=5,866 \%\end{array}$} \\
\hline 40 & 39,16 & & \\
\hline 40 & 44,85 & & \\
\hline 40 & 39,54 & & \\
\hline 40 & 41,52 & & \\
\hline 80 & 76,25 & \multirow[t]{5}{*}{$-7,46$} & \multirow{5}{*}{$\begin{array}{c}\bar{x}=74,036 ; \mathrm{S}=3,7479 ; \\
\mathrm{S}_{\bar{x}}=1,6761 ; \\
\Delta \bar{x}=4,6596 ; \bar{\varepsilon}=6,29 ; \mathrm{S}_{\mathrm{r}}=5,062 \%\end{array}$} \\
\hline 80 & 78,94 & & \\
\hline 80 & 72,26 & & \\
\hline 80 & 69,15 & & \\
\hline 80 & 73,58 & & \\
\hline
\end{tabular}


Для разработки градуировочной модели использовали результаты 5 параллельных измерений каждой концентрации из 5 разных аналитических циклов. Рассчитанное уравнение градуировочного графика имеет вид: $\mathrm{S}=\mathrm{k} \cdot \mathrm{C}+\mathrm{b}=$ $0,060836 \cdot \mathrm{C}+0,018226$, где $\mathrm{S}-$ площадь пика, C - концентрация 2-ДМА-1,3-бис-(ФСТ)П в биоматериале, мкг/г. Градуировочный график представлен на рис. 2.

Коэффициент корреляции (r) равен 0,99562. Методика приемлема по показателю линейности.

Отклонения рассчитанных концентраций градуировочных смесей вещества с тканью гнилостно измененной печени от реального содержания в них 2-ДМА-1,3-бис-(ФСТ)П представлены в табл. 2.

Правильность и прецизионность. Правильность и прецизионность оценивали на основе объединенной выборки результатов анализа холостых образцов биоматериала со стандартными добавками исследуемого вещества.

При этом готовили искусственные смеси ткани гнилостно измененной печени и 2-ДМА-1,3бис-(ФСТ)П с нижним, средним и высоким уровнями содержания вещества (соответственно 12,5, 40 и 80 мкг/г).

Приготовленные искусственные смеси сохраняли 90 минут при $18-22^{\circ} \mathrm{C}$. Затем образцы подвергали анализу (проведение 5 параллельных измерений) в рамках двух аналитических циклов (исследование в первый и последующий дни) по описанной выше схеме.

Количество 2-ДМА-1,3-бис-(ФСТ)П в образцах рассчитывали исходя из площади хроматографического пика, при использовании уравнения градуировочного графика и делали пересчет на навеску.

Результаты определения правильности и прецизионности разработанной методики приведены в табл. 3.

Приводимые в таблице данные подтверждают соответствие методики выбранным для оценки параметрам.

Селективность. По 6 образцов ткани гнилостно измененной печени, не содержащих анализируемое вещество, и по 6 образцов ткани гнилостно измененной печени с введенным стандартом 2-ДМА-1,3-бис-(ФСТ)П в интервале концентраций $7,5 \cdot 10^{-6}-8,0 \cdot 10^{-5}$ г/г исследовали по предлагаемой схеме. На хроматограммах извлечений из биоматериала, не содержащего 2-ДМА-1,3-бис(ФСТ)П, отсутствовали пики со значениями времени удерживания, совпадающими с временем удерживания аналита или близкими к этому значению. Это характеризует методику как селективную.
Предел обнаружения 2-ДМА-1,3-бис-(ФСТ)П в ткани гнилостно измененной печени равен $3,15 \cdot 10^{-6} \Gamma / \Gamma$, предел количественного определения $-4,0 \cdot 10^{-6} \Gamma / \Gamma$.

На основании проведенных исследований можно сделать следующие выводы:

1. Показана целесообразность изолирования 2-диметиламино-1,3-бис-(фенилсульфонилтио) пропана этилацетатом из ткани гнилостно измененной печени в режиме инфузии. Установлены оптимальные параметры извлечения аналита выбранным растворителем.

2. Предложен вариант исследования ткани гнилостно измененной печени с целью подтверждения присутствия в ней рассматриваемого соединения на основе изолирования этилацетатом, очистки посредством макроколоночной адсорбционной хроматографии на силикагеле L 40/100 мкм, идентификации и количественного определения методом ВЭЖХ.

3. Предложенная методика отвечает установленным критериям линейности, правильности, прецизионности, селективности. Пределы обнаружения и количественного определения (ПО и ПКО) составляют соответственно $3,15 \cdot 10^{-6}$ г/г и $3,15 \cdot 10^{-6}$ г/г биоматериала.

\section{ЛИТЕРАТУРА / REFERENCES}

1. Григорьев А.М., Недовизина Г.В., Пирожков М.В. Определение производных и метаболитов бенсультапа (банкола) хроматографическими методами // Судебно-медицинская экспертиза. - 2009. T. 52, № 5. - C. 30-35. [Grigoriev A.M., Nedovizina G.V., Pirozhkov I.V. Detection of bancol derivatives and metabolites by chromatographic methods. Sudebno-meditsinskaya ekspertiza. 2009; 52 (5): 3035 (in Russ.)].

2. Курдиль Н.В., Иващенко О.В., Струк В.Ф., Богомол А.Г. Особенности острых отравлений пестицидами в условиях города: карбаматы, пиретроиды, неоникотиноиды // Медицина неотложных состояний. - 2015. - Т. 66, № 3. - С. 51-57. [Kurdil N.V., Zozulia I.S., Ivashchenko O.V. Features of acute pesticide poisonings in urban area. Meditsina neotlozhnykh sostoyaniy. 2015; 66 (3): 51-57 (in Russ.)].

3. Мельников Н.Н., Новожилов К.В., Белан С.Р. Пестициды и регуляторы роста растений. - М. : Химия, 1995. - 575 с. [Mel'nikov N.N., Novozhilov K.V., Belan S.R. Pesticides and plant growth regulators. M. : Khimiya; 1995: 575 (in Russ.)].

4. Проскряков А.В., Амирханов Д.В. Эффективность банкола в борьбе с колорадским жуком // Агрохимия. - 1991. - № 5. - С. 120-124. [Proskryakov A.V., Amirkhanov D.V. The effectiveness of the bancol in the fight against the Colorado potato beetle. Agrokhimiya. 1991; (5): 120-124 (in Russ.)].

5. Шорманов В.К., Баранов Ю.Н., Дурищын Е.П., Маслов С.В., Прониченко Е.И., Ганиев С.В. Судеб- 
но-химическое определение банкола // Судебномедицинская экспертиза. - 2010. - Т. 53, № 6. C. 39-41. [Shormanov V.K., Baranov Iu.N., Duritsyn E.P., Maslov S.V., Pronichenko E.I., Ganiev S.V. Detection of bancol for the purpose of forensic chemical expertise. Sudebno-meditsinskaya ekspertiza. 2010; 53 (6): 39-41. (in Russ.)].

6. Шорманов В.К., Ким А.В., Дуриџын Е.П. Особенности определения ТМТД в биологическом материале // Судебно-медицинская экспертиза. 2010. - T. 53, № 2. - C. 45-49. [Shormanov V.K., Kim A.V., Duritsyn E.P., Baranov Iu.N. Peculiarities of tetramethyltiuram disulfide detection in the biological material. Sudebno-meditsinskaya ekspertiza. 2010; 53 (2): 45-49 (in Russ.)].

7. Шорманов В.К., Андреева Ю.В., Герасимов Д.А., Маркелов М.Ю., Омельченко В.А. Применение методов обращенно-фазовой хроматографии для идентификации и количественного определения флутамида и близких по структуре веществ в биологических жидкостях // Сорбционные и хроматографические процессы. - 2016. - Т. 16, № 6. C. 868-879. [Shormanov V.K., Andreeva J.V., Gerasimov D.A., Markelov M.Yu., Omelchenko V.A. The use of reverse phase chromatography methods for the identification and quantification of flutamide and similar structures of substances in biological fluids. Sorbtsionnyye i khromatograficheskiye protsessy. 2016; 16 (6): 868-879 (in Russ.)].

8. Bensultap [Электронный pecypc] // Lofter . - Режим доступа:

http://docbook.blog.163.com/blog/static/20832604720 1262412227365/, свободный (20.01.2018). [Bensultap [Electronic resource]. Lofter. Access mode: http://docbook.blog.163.com/blog/static/20832604720 $1262412227365 /$, free $(01 / 20 / 2018)]$.
9. Bensultap [Электронный pecypc] // Pub Chem. Режим доступа: https://pubchem.ncbi.nlm.nih.gov/compound/Bensulta p\#section=Top, свободный (20.01.2018). [Bensultap [Electronic resource]. Pub Chem. Access mode: https://pubchem.ncbi.nlm.nih.gov/compound/Bensulta p\#section=Top, free $(01 / 20 / 2018)$. (in Russ.)].

10. Civelek H.S., Çolak A.M. Effects of Some Plant Extracts and Bensultap on Trichoferus griseus (Fabricius, 1792) (Coleoptera: Cerambycidae) // World Journal of Agricultural Sciences. - 2008. - Vol. 4, N 6. P. 721-725.

11. Kalyaniwala K., Abhilash K., Victor P.J. Cartap Hydrochloride Poisoning // J Assoc. Physicians. India. 2016. - Vol. 64, N 8. - P. 91-92.

12. Kumar A.S., Amalnath D., Dutta T.K. Cartap poisoning: A rare case report // Indian J. Crit. Care Med. 2011. - Vol.15, N 4. - P. 233-235. DOI:10.4103/0972-5229.92075.

13. Kurisaki E., Kato N., Ishida T. Fatal human poisoning with PadanTM: a cartap-containing pesticide // Clinical Toxicology. - 2010. - Vol. 48, N 2. - P. 153155. - DOI:10.3109/15563650903505166.

14. Mikov M., Jecez M., Popovic J. Acute human poisoning with bensultap (Bancol) // Arch. Toxicol. Kinet. Xenobiot. Metab. - 1997. - Vol. 5. - P. 231-233.

15. Park Y., Choe S., Lee H., Jo J., Kim E., Pyo J., Jung J.H. Advanced analytical method of nereistoxin using mixed-mode cationic exchange solid-phase extraction and GC/MS // Forensic Sci. Int. - 2015. Vol. 252. - P. 143-149. - DOI: 10.1016/j.forsciint.2015.04.010.

16. Summary of Toxity Studies on Bensultap. (Development Department, Plant Protection Research, AgroDivision, Taceda Chemical Industries, Ltd.) // J. Pesticide Sci. - 1989. - Vol. 14, N 4. - P. 523-529. 